\title{
ANALISIS FAKTOR YANG MEMPENGARUHI IPK MAHASISWA TERHADAP PENENTUAN KUALITAS PROSES PEMBELAJARAN DENGAN METODE ELECTRE II
}

\author{
Riski Yanti ${ }^{1}$, Agus Perdana Windarto ${ }^{2}$, Suhada $^{3}$ \\ ${ }^{1}$ Mahasiswa Program Studi Sistem Informasi STIKOM Tunas Bangsa Pematang Siantar \\ ${ }^{2,3}$ STIKOM Tunas Bangsa Pematangsiantar, Indonesia \\ Email: ${ }^{1}$ riskiyanti432@gmail.com, ${ }^{2}$ agus.perdana@ amiktunasbangsa.ac.id, ${ }^{3}$ suhada.atb@ gmail.com
}

\begin{abstract}
Abstrak
Penelitian ini bertujuan untuk faktor apa yang mempengaruhi nilai IPK Mahasiswa di STIKOM Tunas Bangsa Pematangsiantar. Data yang digunakan didapat kan dengan memberikan kuesioner kepada mahasiswa STIKOM Tunas Bangsa Pematangsiantar. Dengan alternatif yang digunakan yaitu kurikulim, kecerdasan, absensi, dan nilai. Sedangkan kriteria yang digunakan yaitu namanama responden yang menjawab suatu pertanyaan. Metode yang digunakan dalam penelitian ini yaitu ELECTRE II. Dari hasil perhitungan ELECTRE II didapatkan alternative ketiga A3 sebagai ranking pertama, A2 sebagai rangking kedua, A4 sebagai rangking ketiga, dan A1 sebagai alternatif terakhir. Diharapkan penelitian ini dapat di gunakan oleh pihak pendidikan sebagai bahan ajaran untuk keberhasilan dan kemajuan Akademik mahasiswa.
\end{abstract}

Kata kunci: Mahasiswa, IPK, Sistem Pendukung Keputusan, ELECTRE II

\begin{abstract}
This study aims at what factors influence the value of Student GPA in StikomTunas Bangsa Pematangsiantar. Data used is obtained by giving questionnaires to students of STIKOM Tunas Bangsa Pematangsiantar. With alternatives used, namely curriculim, intelligence, absenteeism, and value. While the criteria used are the names of respondents who answer a question. The method used in this study is Electre II. From the results of the ELECTRE II calculation, the third alternative A3 is obtained as the first rank, A2 as the second rank, A4 as the third rank, and Al as the last alternative. It is hoped that this research can be used by the education as teaching material for the students' academic success and progress.
\end{abstract}

Keywords: Students, GPA, Decision Support System, ELECTRE II

\section{PENDAHULUAN}

Perguruan Tinggi merupakan Suatu lembaga utama pendidikan yang dilakukan untuk membentuk peserta didik menjadi seseorang yang memiliki kemampuan akademis dan profesional yang dapat menerapkan, mengembangkan, dan menciptakan ilmu pengetahuan di lingkungan masyarakat. Di Indonesia secara umum, terdapat dua jenis perguruan tinggi yaitu yang dikelola oleh pihak swasta atau perguruan tinggi swasta dan perguruan tinggi negeri. Pada saat ini perguruan tinggi negeri masih menjadi favorit, namun di masa yang akan datang. seperti yang terjadi di luar negeri, perguruan tinggi swasta lebih diminati karena mampu menghasilkan lulusan yang lebih berkualitas dan berdaya saing [1]. Untuk menghasilkan peserta didik yang berkualitas pihak perguruan tinggi harus memberikan rekomendasi ilmu yang dapat membantu menunjang proses belajar peserta didik tersebut.

STIKOM Tunas Bangsa Pematangsiantar memiliki suatu visi yaitu"Menjadi Sekolah Tinggi yang unggul di bidang ilmu komputer dalam tatanan global pada tahun 2025" itu berarti bahwa visi tersebut memberikan rekomendasi terhadap mahasiswa agar mampu menerapkan ilmu pengetahuan dan mampu bersaing secara global. Untuk itu IPK menjadi salah satu prioritas utama dalam persaingan global dibidang komputer sehingga visi tersebut bisa berjalan dan Terlaksana dengan baik.

Kualitas belajar merupakan salah satu faktor yang menentukan peningkatan mutu pendidikan. Kualitas belajar dapat dilihat dari cara mahasiswa belajar dan media yang digunakan dalam menghasilkan proses dan hasil belajar yang optimal. Oleh karena itu meningkatkan kuliatas belajar harus diperhatikan dengan seksama karena merupakan salah satu faktor untuk meningkatkan prestasi belajar. Prestasi belajar merupakan suatu hasil penilaian dibidang pengetahuan, keterampilan dan sikap sebagai hasil belajar yang dinyatakan dalam bentuk nilai.

Hal-hal yang menjadi hambatan mahasiswa saat ini adalah masalah IPK. IPK atau Indeks Prestasi Kumulatif merupakan keseluruan hasil nilai yang didapat mahasiswa dari semester yang telah dilalui. Semakin besar angka yang diperoleh mahasiswa maka semakin baik prestasi akademik yang mereka ukir. Banyak Mahasiswa beranggapan bahwa nilai IPK merupakan hal utama yang harus dikejar, sehingga semua Mahasiswa berlomba-lomba untuk mendapatkan nilai IPK Tertinggi supaya kedepannya mereka dengan mudah bisa mendapatkan pekerjaan, namun nilai IPK Tinggi tidak menjamin keberhasilan seseorang dalam mencari pekerjaan karena nilai IPK bukan suatu prioritas utama.

Upaya untuk meningkatkan keberhasilan mahasiswa perlu diadakan suatu Evaluasi. Evaluasi artinya penilaian terhadap tingkat keberhasilan mahasiswa dalam mencapai tujuan yang telah ditetapkan sehingga dengan adanya Evaluasi ini dapat membantu memotivasi mahasiswa dalam memperbaiki proses belajarnya. Seorang Mahasiswa harus memiliki Soft skill, yakni mahasiswa harus memiliki kemampuan kepribadian yang menjadi suatu faktor untuk mencapai kesuksesan pada pendidikan yang ditempuh. Selain itu mahasiswa dituntut untuk belajar dan belajar, namun banyak mahasiswa yang tidak menerapkan hal itu sehingga proses belajar tersebut dapat mempengaruhi nilai IPK. 
Melihat penurunan IPK yang semakin turun pada Mahasiswa yang semakin tinggi tingkatnya, peneliti mencoba mencari penyebab IPK menurun dengan beberapa faktor yang menjadi penentu dan digunakan dalam menentukan faktor yang mempengaruhi nilai IPK mahasiswa. Faktor yang Pertama adalah Kurikulum, bahan pengajaran yang sulit ataupun tidak menarik dapat membuat mahasiswa malas belajar. Faktor Kedua adalah kecerdasan yaitu setiap orang memiliki kecerdasan atau kemampuan yang berbeda-beda sehingga tidak semua orang dapat memahami pelajaran yang telah diberikan dengan waktu singkat. Faktor Ketiga adalah Absensi, jika mahasiwa itu jarang hadir dalam mata perkuliahan maka dapat mempengaruhi nilai IPK. Dan Faktor Terakhir Nilai adalah jika nilai rendah maka dapat mempengaruhi IPK. Pemilihan metode Electre II ini digunakan untuk perangkingan dengan tipe kriteria yang sederhana dalam arti threshold-nya sama untuk semua kriteria sehingga dapat mempermudah dalam membantu menemukan faktor-faktor apa saja yang mempengaruhi IPK mahasiswa sehingga hasil output dari pemilihan metode ini dapat menjadi bahan evaluasi yang baik bagi mahasiswa.

Salah satu jurnal yang menjadi referensi dalam penulisan ini yaitu penelitian yang dilakukan oleh [1]. Di dalam jurnal tersebut peneliti melakukan penelitian dalam menganalisis faktor-faktor yang mempengaruhi prestasi belajar mahasiswa dengan indikator yang digunakan yaitu Kualitas Pengajaran, kemandirian belajar, lingkungan keluarga dalam belajar, belajar dengan nilai, konsentrasi belajar, pola makan dan keinginan, penunjang, pola asuh. jurnal lain yang menjadi acuan adalah Faktor Terbesar Rendahnya Minat Ber-KB (Keluarga Berencana) Dengan Metode Electre II penelitian yang dilakukan oleh Ledis Pebriani Purba yang membahas tentang Untuk mengetahui faktor-faktor apa yang menjadi faktor terbesar rendahnya minat ber kb dengan atribut yang digunakan yaitu Resiko Kesehatan, Ajaran Agama, Banyak Anak Banyak Rezeki [2].

Berdasarkan latar belakang diatas, penulis mengangkat judul "Analisis Faktor yang mempengaruhi IPK Mahasiswa Terhadap Penentuan Kualitas Proses Pembelajaran Dengan Metode ELECTRE II", diharapkan dengan penelitian ini dapat membantu Mahasiswa dalam menemukan faktor-faktor yang mempengaruhi IPK.

\section{TEORITIS}

\subsection{Sistem Pendukung Keputusan}

"Sistem Pendukung Keputusan (SPK) merupakan suatu pendekatan atau metodelogi untuk mendukung keputusan. SPK menggunakan CBIS (Computer Based Information System) yang fleksibel, interaktif dan dapat di atasi, yang dikembangkan untuk mendukung solusi untuk masalah manajemen spesifik yang tidak terstruktur. SPK menggunakan data, memberikan antarmuka pengguna yang mudah dan dapat menggabungkan pemikiran pengambil keputusan" [3].

\subsection{Algoritma Elimination Et Choix Traduisant La Realite II (ELECTRE II)}

Metode ELECTRE II sebagai salah satu metode MADM secara luas diakui mempunyai performa yang baik untuk menganalisis kebijakan yang melibatkan kriteria kualitatif dan kuantitatif. Metode ELECTRE II telah berkembang melalui sejumlah versi (I, II, III, IV, 1S). Semua versi didasarkan pada konsep dasar yang sama namun secara operasional berbeda. Metode ELECTRE II didesain untuk pemilihan sedangkan ELECTRE II digunakan untuk perankingan. Kedua versi ini menggunakan tipe kriteria yang sederhana, dalam arti nilai threshold-nya sama untuk semua kriteria sedangkan versi yang lain menggunakan pseudo criteria yang nilai threshold-nya tidak sama untuk semua kriteria [2].

\subsection{Multi Criteria Decision Making (MCDM)}

Multi Criteria Decision Making merupakan disiplin ilmu yang digunakan untuk memecahkan masalah dalam pengambilan keputusan yang kompleks dan melibatkan lebih dari satu kriteria yang saling bertentangan dan banyak alternatif dalam menentukan pilihan keputusan[4].

\subsection{Multiple Attribute Decision Making (MADM)}

"Multiple Attribute Decision Making (MADM) adalah suatu metode yang digunakan untuk mencari alternatif optimal dari sejumlah alternatif dengan kriteria tertentu. Inti dari MADM adalah menentukan bobot untuk setiap atribut, kemudian dilanjutkan dengan proses perengkingan yang akan menyelesaikan alternatif yang sudah diberikan[5]

\section{ANALISA DAN PEMBAHASAN}

\subsection{Analisis Data}

Dalam penelitian, data yang digunakan akan diolah dari hasil kuesioner yang diberikan kepada mahasiswa STIKOM Tunas Bangsa semester 3, 5, dan 7. Kriteria yang digunakan dalam kuesioner yaitu:

1. Kurikulum

2. Kecerdasan

3. Absensi 
4. Nilai

Kriteria terdiri dari pertanyaan yang diajukan ke mahasiswa yang diberikan. Kuesioner yang telah dilakukan selanjutnya mencari perengkingan dari kriteria yang digunakan. Data yang digunakan menggunakan jenis statistik inferensial. Statistik inferensial adalah statistik yang berkaitan dengan analisis data (sampel), kemudian diambil kesimpulan yang digeneralisasikan kepada seluruh populasi dan digunakan untuk menarik inferensi dari sampel ke populasi [6].

Setiap kriteria terdiri dari 2 atau lebih pertanyaan yang diajukan ke mahasiswa yang diberikan dengan menggunakan skalalinker 5 yang terdiri dari SS (Sangat Setuju), S (Setuju), N (Netral), TS (Tidak Setuju), dan STS (Sangat Tidak Setuju). Kuesioner yang telah dilakukan selanjutnya mencari perengkingan dari kriteria yang digunakan. Data yang digunakan menggunakan jenis statistik inferensial. Statistik inferensial adalah statistik yang berkaitan dengan analisis data (sampel), kemudian diambil kesimpulan yang digeneralisasikan kepada seluruh populasi dan digunakan untuk menarik kesimpulan dari sampel ke populasi. Kemudian data diolah menggunakan metode ELECTRE II dan akan di buat dengan mengunakan aplikasi $v b$ net.

\subsection{Perhitungan ELECTRE II.}

Untuk mendapatkan hasil dari penelitian yang dilakukan, berikut uraian perhitungan manual yang akan di jelaskan. Berikut data yang diperoleh dalam penelitian ini dapat dilihat pada tabel 1 .

Tabel 1. Data Alternatif 1

\begin{tabular}{|c|c|c|c|c|c|c|c|c|c|c|}
\hline \multirow{2}{*}{ Alternatif } & \multicolumn{10}{|c|}{ Kriteria } \\
\hline & C1 & $\mathrm{C2}$ & C3 & C4 & C5 & C6 & C7 & C8 & C9 & C10 \\
\hline Kuriulum & 2,67 & 3,67 & 3,67 & 3,67 & 3,67 & 4 & 3,67 & 3,33 & 3,67 & 3,67 \\
\hline kecerdasan & 4 & 4,33 & 3,00 & 3,33 & 4 & 3,33 & 4 & 3,33 & 3,33 & 3,67 \\
\hline Absensi & 3 & 5 & 5 & 4,50 & 4 & 3,50 & 4,50 & 4 & 4,50 & 4 \\
\hline Nilai & 3 & 4,50 & 4,50 & 4 & 3,50 & 4 & 4,50 & 4,50 & 4,50 & 4 \\
\hline \multicolumn{11}{|c|}{ Tabel 2. Data Alternatif 2} \\
\hline \multirow{2}{*}{ Alternatif } & \multicolumn{10}{|c|}{ Kriteria } \\
\hline & C11 & $\mathrm{C12}$ & $\mathrm{C13}$ & C14 & $\mathbf{C 1 5}$ & C16 & C17 & $\mathrm{C18}$ & $\mathrm{C19}$ & $\mathrm{C20}$ \\
\hline Kuriulum & 4,33 & 3,33 & 4 & 4,33 & 3,67 & 4,67 & 3,67 & 3,67 & 3,67 & 3,33 \\
\hline kecerdasan & 4 & 3,67 & 4 & 4,33 & 4 & 4,33 & 3,67 & 3,67 & 3,33 & 3 \\
\hline Absensi & 5 & 4,50 & 4 & 4,50 & 5 & 4 & 4 & 4 & 4,50 & 2,50 \\
\hline Nilai & 4,50 & 4 & 4,50 & 5 & 5 & 4,50 & 4 & 4 & 5 & 3,50 \\
\hline
\end{tabular}

Normalisasi Matriks Keputusan.

1. Normalisasi matrik keputusan dapat dilakukan dengan persamaan :

$$
\begin{aligned}
& r i j=\frac{X_{i_{j}}}{\sum_{i=1}^{m} X_{i_{j}}^{2}} \\
& X_{1}=\sqrt{(2,67)^{2}+(4)^{2}+(3)^{2}+(3)^{2}} \\
& =36,67 \\
& r_{11}=\frac{2,67}{36,67}=0,0727 \\
& r_{21}=\frac{4}{36,67}=0,1091 \\
& r_{31}=\frac{3}{36,67}=0,0818 \\
& r_{41}=\frac{3}{36,67}=0,0818 \\
& X_{2}=\sqrt{(3,67)^{2}+(4,33)^{2}+(5)^{2}+(4,50)^{2}} \\
& =67,69 \\
& r_{12}=\frac{3,67}{67,69}=0,0542 \\
& r_{22}=\frac{4,33}{67,69}=0,0640 \\
& r_{32}=\frac{5}{67,69}=0,0739 \\
& r_{42}=\frac{4.50}{67,69}=0,0665
\end{aligned}
$$

Tabel 3. Normalisasi Nilai Matriks

\begin{tabular}{cccccccccc}
\hline $\mathbf{C}_{1}$ & $\mathbf{C}_{\mathbf{2}}$ & $\mathbf{C}_{\mathbf{3}}$ & $\mathbf{C}_{\mathbf{4}}$ & $\mathbf{C}_{\mathbf{5}}$ & $\mathbf{C}_{\mathbf{6}}$ & $\mathbf{C}_{7}$ & $\mathbf{C}_{\mathbf{8}}$ & $\mathbf{C}_{\mathbf{9}}$ & $\mathbf{C}_{\mathbf{1 0}}$ \\
\hline 0,0727 & 0,0542 & 0,0633 & 0,0719 & 0,0765 & 0,0922 & 0,0609 & 0,0658 & 0,0663 & 0,0747
\end{tabular}




$\begin{array}{llllllllll}0,1091 & 0,0640 & 0,0518 & 0,0653 & 0,0835 & 0,0769 & 0,0665 & 0,0658 & 0,0603 & 0,0747 \\ 0,0818 & 0,0739 & 0,0863 & 0,0882 & 0,0835 & 0,0807 & 0,0748 & 0,0789 & 0,0814 & 0,0814 \\ 0,0818 & 0,0665 & 0,0777 & 0,0784 & 0,0730 & 0,0922 & 0,0748 & 0,0888 & 0,0814 & 0,0814\end{array}$

\begin{tabular}{cccccccccc}
\hline $\mathbf{C}_{\mathbf{1 1}}$ & $\mathbf{C}_{\mathbf{1 2}}$ & $\mathbf{C}_{\mathbf{1 3}}$ & $\mathbf{C}_{\mathbf{1 4}}$ & $\mathbf{C}_{\mathbf{1 5}}$ & $\mathbf{C}_{\mathbf{1 6}}$ & $\mathbf{C}_{\mathbf{1 7}}$ & $\mathbf{C}_{\mathbf{1 8}}$ & $\mathbf{C}_{\mathbf{1 9}}$ & $\mathbf{C}_{\mathbf{2 0}}$ \\
\hline 0,0661 & 0,0629 & 0,0711 & 0,0634 & 0,0526 & 0,0782 & 0,0747 & 0,0747 & 0,0611 & 0,1081 \\
0,0610 & 0,0691 & 0,0711 & 0,0634 & 0,0574 & 0,0726 & 0,0747 & 0,0747 & 0,0555 & 0,0973 \\
0,0762 & 0,0849 & 0,0711 & 0,0658 & 0,0718 & 0,0670 & 0,0814 & 0,0814 & 0,0750 & 0,0811 \\
0,0686 & 0,0754 & 0,0800 & 0,0731 & 0,0718 & 0,0754 & 0,0814 & 0,0814 & 0,0833 & 0,1135 \\
\hline
\end{tabular}

2. Pembobotan pada matriks yang telah dinormalisasi Matriks V merupakan hasil perkalian R dengan W (bobot), dimana w (bobot) dapat dilihat pada tabel 4.

Tabel 4. Matriks Setelah Dinormalisasikan $\left(\mathrm{R}^{*} \mathrm{~W}\right)$

\begin{tabular}{cccccccccc}
\hline $\mathbf{C}_{\mathbf{1}}$ & $\mathbf{C} \mathbf{2}$ & $\mathbf{C}_{\mathbf{3}}$ & $\mathbf{C}_{\mathbf{4}}$ & $\mathbf{C}_{\mathbf{5}}$ & $\mathbf{C}_{\mathbf{6}}$ & $\mathbf{C}_{\mathbf{7}}$ & $\mathbf{C}_{\mathbf{8}}$ & $\mathbf{C}_{\mathbf{9}}$ & $\mathbf{C}_{\mathbf{1 0}}$ \\
\hline 0,0069 & 0,0049 & 0,0054 & 0,0058 & 0,0058 & 0,0066 & 0,0041 & 0,0041 & 0,0038 & 0,0039 \\
0,0104 & 0,0058 & 0,0044 & 0,0053 & 0,0064 & 0,0055 & 0,0044 & 0,0041 & 0,0034 & 0,0039 \\
0,0078 & 0,0067 & 0,0074 & 0,0071 & 0,0064 & 0,0058 & 0,0050 & 0,0049 & 0,0047 & 0,0043 \\
0,0078 & 0,0060 & 0,0067 & 0,0063 & 0,0056 & 0,0066 & 0,0050 & 0,0055 & 0,0047 & 0,0043 \\
\hline $\mathbf{C}_{\mathbf{1 1}}$ & $\mathbf{C}_{\mathbf{1 2}}$ & $\mathbf{C}_{\mathbf{1 3}}$ & $\mathbf{C}_{\mathbf{1 4}}$ & $\mathbf{C}_{\mathbf{1 5}}$ & $\mathbf{C}_{\mathbf{1 6}}$ & $\mathbf{C}_{\mathbf{1 7}}$ & $\mathbf{C}_{\mathbf{1 8}}$ & $\mathbf{C}_{\mathbf{1 9}}$ & $\mathbf{C}_{\mathbf{2 0}}$ \\
\hline 0,0031 & 0,0027 & 0,0027 & 0,0021 & 0,0015 & 0,0019 & 0,0014 & 0,0011 & 0,0006 & 0,0005 \\
0,0029 & 0,0030 & 0,0027 & 0,0021 & 0,0016 & 0,0017 & 0,0014 & 0,0011 & 0,0005 & 0,0005 \\
0,0036 & 0,0036 & 0,0027 & 0,0022 & 0,0021 & 0,0016 & 0,0016 & 0,0012 & 0,0007 & 0,0004 \\
0,0033 & 0,0032 & 0,0030 & 0,0024 & 0,0021 & 0,0018 & 0,0016 & 0,0012 & 0,0008 & 0,0005 \\
\hline
\end{tabular}

3. Menentukan himpunan concordance dan discordance index Himpunan concordance, sebagai berikut:
$C 12=$
$V 11 \geq V 21=0,0727 \geq 0,1091$
$V 12 \geq V 22=0,0542 \geq 0,0640$
$V 13 \geq V 23=0,0633 \geq 0,0863$
$V 14 \geq V 24=0,0719 \geq 0,0653$
$V 15 \geq V 25=0,0765 \geq 0,0835$
$V 16 \geq V 26=0,0922 \geq 0,0769$
$V 17 \geq V 27=0,0609 \geq 0,0665$
$V 18 \geq V 28=0,0658 \geq 0,0658$
$V 19 \geq V 29=0,0663 \geq 0,0603$
$V 110 \geq V 210=0,0747 \geq 0,0747$

Dan seterusnya hingga D43 Sehingga didapatkan himpunan concordance nya. Menentukan himpunan discordance, sebagai berikut :

D12 =

$V 21 \geq V 11=0,1091 \geq 0,0727$

$V 22 \geq V 12=0,0640 \geq 0,0542$

$V 23 \geq V 13=0,0863 \geq 0,0633$

$V 24 \geq V 14=0,0653 \geq 0,0719$

$V 25 \geq V 15=0,0835 \geq 0,0765$

$V 26 \geq V 16=0,0769 \geq 0,0922$

$V 27 \geq V 17=0,0665 \geq 0,0609$

$V 28 \geq V 18=0,0658 \geq 0,0658$

$V 29 \geq V 19=0,0603 \geq 0,0663$

$V 210 \geq V 110=0,0747 \geq 0,0747$

Dan seterusnya hingga D43 Sehingga didapatkan himpunan discordance nya.

4. Hitung matriks concordance dan discordance. Menghitung concordance, sebagai berikut :

$C 12=W 1+W 3+W 5+W 6+W 8$

$=0,0952+0,0857+0,0762+0,0714+0,0619$

$=0,3905$

dan seterusnya hingga C2019. Nilai dari komponen matriks disusun berdasarkan himpunan concordance dengan bobot (W) dan dijumlahkan, sehingga menghasilkan matriks concordance sebagai berikut :

Tabel 5. Matriks Concordance

\begin{tabular}{lllll}
\hline Concordance & A1 & A2 & A3 & A4 \\
\hline
\end{tabular}




\begin{tabular}{ccccc}
\hline A1 & - & 0,6000 & 0,1381 & 0,1762 \\
A2 & 0,6238 & - & 0,2381 & 0,2381 \\
A3 & 0,9000 & 0,9714 & - & 0,7571 \\
A4 & 0,9000 & 0,9238 & 0,5762 & - \\
\hline
\end{tabular}

5. Menghitung discordance. Untuk menghitung nilai dari elemen pada matriks discordance adalah dengan membagi maksimum selisih nilai kriteria yang termasuk dalam subset discordance dengan maksimum selisih nilai seluruh kriteria yang ada, secara matematisnya sebagai berikut :

$$
D_{k l=} \frac{\operatorname{Max}\left\{\begin{array}{c}
(0,0069-0,0104) ;(0,0049-0,0058) ;(0,0041-0,0044) ; \\
(0,0038-0,0034) ;(0,0031-0,0029) ;(0,0027-0,0030) ; \\
(0,0015-0,0016)
\end{array}\right\}}{\operatorname{Max}\left\{\begin{array}{c}
(0,0069-0,0104) ;(0,0049-0,0058) ;(0,0054-0,0044) ; \\
(0,0058-0,0053) ;(0,0058-0,0064) ;(0,0066-0,0058) ; \\
(0,0039-0,003) ;(0,0041-0,0041) ;(0,0038-0,0034) ; \\
(0,0027-0,0027) ;(0,0031-0,0029) ;(0,0027-0,0030) ; \\
(0,0006-0,0021) ;(0,0015-0,0016) ;
\end{array}\right\}}
$$

Dan seterusnya sampai D1019, Sehingga diperoleh matriks discordance sebagai berikut:

Tabel 6. Matriks Discordance

\begin{tabular}{ccccc}
\hline Discordance & A1 & A2 & A3 & A4 \\
\hline A1 & - & 1 & 1 & 1 \\
A2 & 1 & - & 1 & 0,8547 \\
A3 & 0,4174 & 0,8775 & - & 1 \\
A4 & 0 & 1 & 1 & - \\
\hline
\end{tabular}

6. Menentukan matriks dominan concordance dan discordance.

a. Matriks dominan concordance, Menghitung matriks dominan concordance Threshold didapat dari penjumlahan seluruh elemen matriks dibagi ukuran matriks sehingga matriks dominannya adalah :

Tabel 7. Matriks Dominan Concordance

\begin{tabular}{ccccc}
\hline Dominan Concordance & A1 & A2 & A3 & A4 \\
\hline A1 & - & 0 & 0 & 0 \\
A2 & 0 & - & 0 & 0 \\
A3 & 0 & 0 & - & 0 \\
A4 & 0 & 0 & 0 & - \\
\hline
\end{tabular}

b. Matriks dominan discordance, Menghitung matriks dominan Disconcordance Threshold didapat dari penjumlahan seluruh elemen matriks dibagi ukuran matriks yang terdapat pada persamaan (8). Sehingga matriks dominannya adalah:

Tabel 8. Matriks Dominan Discordance

\begin{tabular}{ccccc}
\hline Dominan Discordance & A1 & A2 & A3 & A4 \\
\hline A1 & - & 1 & 1 & 1 \\
A2 & 1 & - & 1 & 1 \\
A3 & 1 & 1 & - & 1 \\
A4 & 1 & 1 & 1 & - \\
\hline
\end{tabular}

7. Menghitung indeks concordance murni dan Discordance murni.

a. Concordance murni, Untuk mencari nilai concordance murni dapat dilihat sebagai berikut.

$$
\begin{aligned}
& C 1=0,6238+0,9000+0,9000-(0,6000+0,1381+0,1762) \\
& =1,5095 \\
& C 2=0,6238+0,2381+0,2381-(0,6000+0,9714+0,9238) \\
& =-1,3952 \\
& C 3=0,9000+0,9714+0,7551-(0,1381+0,2381+0,5762) \\
& =1,6762 \\
& C 4=0,9000+0,9238+0,5762-(0,1762+0,2381+0,7571) \\
& =1,2286
\end{aligned}
$$

b. Discordance murni, Untuk mencari nilai discordance murni dapat dilihat sebagai berikut.

$$
\begin{aligned}
& D 1=1+1+1-(1+0,4174+0)=2 \\
& D 2=1+1+0,8547-(1+0,8775+1)=-0,0228 \\
& D 3=0,4174+0,8775+1-(1+1+1)=-0,6703 \\
& D 4=0+1+1-(1+0,8547+1)=-0,8894
\end{aligned}
$$

8. Setelah kedua indeks telah dihitung, maka untuk mendapatkan alternatif terbaik adalah dengan mencari nilai rata rata dari kedua peringkat indeks concordance murni dan discordance murni. sehingga didapatkan peringkat peringkat sebagai berikut berdasarkan tabel 9. 
Tabel 9. Perhitungan alternatif terbaik

\begin{tabular}{ccccccc}
\hline Faktor & Concordance & Rangking & Discordance & Rangking & $\begin{array}{c}\text { Average } \\
\text { Rank }\end{array}$ & $\begin{array}{c}\text { Final } \\
\text { Rank }\end{array}$ \\
\hline A1 & $-1,5095$ & 4 & 2 & 4 & 4 & 4 \\
A2 & $-1,3952$ & 3 & $-0,0228$ & 1 & 2 & 2 \\
A3 & 1,6762 & 1 & $-0,6703$ & 2 & 1 & 1 \\
A4 & 1,2286 & 2 & $-0,8894$ & 3 & 3 & 3 \\
\hline
\end{tabular}

\section{KESIMPULAN}

Berdasarkan pembahasan sebelumnya dapat disimpulkan bahwa :

1. Hasil penelitian yang di peroleh dapat disimpulkan bahwa perhitungan ELECTRE II dan aplikasi vb net dapat di gunakan dalam untuk menyelesaikan sebuah faktor yang mempengaruhi IPK mahasiswa terhadap Penentuan Kualitas Proses Pembelajaran dengan menggunakan metode ELECTRE II dan dapat disimpulkan faktor IPK mahasiswa dapat dilihat dari hasil akhir yaitu A3 dengan alternatif absensi yang memiliki nilai concordance 1.6762 dan untuk nilai discordancenya memiliki nilai 0.6703 dengan Averange dan final rank nya sama sama memiliki nilai 1 .

2. Hasil yang diperoleh menggunakan sebuah metode algoritma yaitu ELECTRE II yang di uji menggunkan aplikasi $v b$ net dengan memasukan data hasil dari perhitungan manual ELECTRE II. di simpulkan bahwa ELECTRE II adalah sebuah metode yang mudah untuk membuat suatu perangkingan.

\section{REFERENCES}

[1] V. Anggresta, Analisis Faktor-Faktor Yang Mempengaruhi Prestasi Belajarmahasiswa Fakultas Ekonomi Universitas Negeri Padang, Economica, Vol. 4, No. 1, 2016.

[2] L. P. Purba, A. P. Windarto, And A. Wanto, Faktor Terbesar Rendahnya Minat Ber-Kb ( Keluarga Berencana ) Dengan Metode Electre II, Pp. 369-374, 2018.

[3] H. Bartolomius And S. Palupi, Sistem Pendukung Keputusan Penerimaan Asisten Laboratorium Komputer Menggunakan Metode Simple Additive Weighting (Studi Kasus Pada Laboratorium Komputer Stmik Widya Cipta Dharma Samarinda), Pros. Semin. Ilm. Nas. Teknol. Komput. (Senatkom 2015), Vol. 1, No. Senatkom, Pp. 90-95, 2015.

[4] Sanusi And J. Husna, Fuzzy Mcdm Untuk Pemilihan Tempat Wisata Berbasis Web, J. Ilm. Rekayasa Dan Manaj. Sist. Inf., Vol. 4, No. 1, 2018.

[5] M. Hidayat And M. Alif Muafiq Baihaqi, Sistem Pendukung Keputusan Untuk Pemilihan Hotel Dengan Simple Additive Weighting (Saw) Berbasis Web=Semin. Nas. Teknol. Inf. Dan Multimed., Pp. 61-66, 2016.

[6] T. Aurora Lubis, Zulkifli, And Firmansyah, Model Perilaku Keuangan Manajer Bank Bumn Tbk. Di Kota Jambi, J. Penelit. Univ. Jambi Seri Hum., Vol. 17, No. 0852-8349, Pp. 9-17, 2015. 